\title{
EXPLORANDO CONFLICTOS ENTRE COMUNIDADES INDÍGENAS Y LA INDUSTRIA MINERA EN CHILE: LAS TRANSFORMACIONES SOCIOAMBIENTALES DE LA REGIÓN DE TARAPACÁ Y EL CASO DE LAGUNILLAS
}

\author{
EXPLORING CONFLICTS BETWEEN INDIGENOUS COMMUNITIES \\ AND THE MINING INDUSTRY IN CHILE: THE SOCIOENVIRONMENTAL \\ TRANSFORMATIONS OF THE TARAPACA REGION AN THE CASE OF LAGUNILLAS
}

Hugo Romero Toledo' ${ }^{1}$ Angélica Videla ${ }^{2}$ y Felipe Gutiérrez ${ }^{3}$

\begin{abstract}
Resumen
Este artículo explora los conflictos socioambientales mineros, a partir de la contradicción entre el crecimiento económico de Chile, que es fuertemente dependiente de la producción de minerales para el mercado global, y los acuerdos nacionales e internacionales que apuntan al reconocimiento y protección de los pueblos originarios así como también del territorio que habitan. En este sentido, se analiza la problemática de acceso y control del agua, puesto que se ha registrado daño ambiental sobre recursos hídricos localizados en territorios de comunidades. Para ello la investigación entrega una serie de elementos que le dan forma a las interacciones y a los conflictos entre empresas mineras y comunidades indígena, como lo son la importancia de las dinámicas de la población andina indígena, y el uso fluido que hacen del espacio urbano y rural,

el proceso de reconocimiento y formalización del pueblo aymara, las comunidades y los territorios indígenas versus la territorialización de la industria minera desde los años ochenta. Para ilustrar estos procesos se presenta el caso del humedal de Lagunillas localizado en la precordillera de la región de Tarapacá.
\end{abstract}

Palabras claves: Conflictos socioambientales - aymara - minería -Tarapacá. Abstract
This article explores socioenvironmental mining conflicts, from the contradiction
between economic growth in Chile, which strongly depends on mineral production for
global markets, and the national and international agreements that aim to protect
indigenous communities and the environment where they live. One of the main issues
centers on water resources located in these territories.
In this sense, our research is also focused the elements that shape interactions and
conflicts between companies and indigenous communities, such as the importance
of the dynamics of the Indigenous Andean population, and the fluid use that they
make of urban and rural space, the process of recognition and formalization of the
Indigenous people, communities and territories, and the territorialization of the
mining industry since the 1980 . These processes are illustrated through the case of
the Lagunillas wetlands, located in the foothills of the Tarapacá region.

Keywords: Socioenvironmental conflicts - aymaras - mining -Tarapacá.

Recibido: diciembre 2015. Aceptado: agosto 2016.

\section{* Introducción}

El norte de Chile es conocido por ser uno de los lugares de extrema aridez en el mundo. Pese a lo anterior, este extenso territorio ha permanecido habitado por grupos humanos desde hace aproximadamente 12 mil años. Actualmente, existen al menos tres pueblos originarios en este espacio, que se encuentran luchando por reconocimiento político y derechos territoriales. Estos pueblos -que residen en el altiplano y la precordillera- son los aymara, quechua y atacameño o likan-antai, cuyas prácticas socioambientales son ancestrales y trascienden los límites geopolíticos de la cordillera de los Andes. El norte de Chile, además, es rico en minerales, lo que ha atraído históricamente a grandes compañías mineras públicas y privadas, que han ejercido una creciente demanda por tierra, agua y energía para sus procesos industriales, y que en base a marcos legales ad hoc, han transformado a la minería en la actividad económica más importante del país. De esta forma, ha emergido una importante contradicción, que se ha acentuado en los últimos treinta años: el crecimiento económico de Chile, fuertemente dependiente de la producción de minerales para el mercado global, choca con los acuerdos nacionales e internacionales que apuntan al reconocimiento y protección de las comunidades indígena y el medio ambiente en que viven, los cuales han sido recientemente reconocidos y negociados. Sin embargo, en Chile los movimientos sociales contra la minería están menos desarrollados que en otras partes de América Latina, pese a lo extensivo e intensivo de la industria minera en el país.

I Doctor en Geografía Humana. Director del Observatorio Regional, Universidad Católica de Temuco e Investigador del Centro de Estudios de Conflicto y Cohesión Social (COES).CHILE. Email: hugo.romero@uct.cl.

2 Cientista Política, $\mathrm{Mg}$ (C) en Estudios Interculturales. Coordinadora del Observatorio Regional, Universidad Católica de Temuco, CHILE. Email: avidela@uct.cl

3 Geógrafo. Asistente de investigación del Observatorio Regional, Universidad Católica de Temuco. CHILE. Email: fgutierrezzoro@alu.uct.cl 
Este artículo explora cómo esta contradicción se desarrolla en el norte de Chile. Para ello nos adentraremos en el concepto de extractivismo y su aplicación a la minería, para con esta relación entender el concepto de territorialización. En la segunda sección se analiza la conceptualización de articulación identitaria indígena y se presenta el caso de las comunidades andinas en el norte de Chile, posteriormente se expone la metodología de investigación. En las últimas tres secciones se presentan los resultados: en primer lugar, se analiza el proceso de territorialización de la inversión minera en Chile y en la región de Tarapacá, luego, se presenta la articulación identitaria indígena en el norte de Chile, y en tercer lugar, se presenta el caso de Lagunillas, en el que se expresa la contradicción entre el crecimiento minero y la reorganización indígena. Por último, se presentan conclusiones sobre el proceso chileno y las futuras líneas de investigación.

\section{* Extractivismo minero en AmÉrica latina}

Como resultado del proceso de colonización, América Latina fue especializada tempranamente en la explotación intensiva de materias primas, especialmente minerales, lo que ha generado a lo largo del tiempo un patrón de crecimiento económico con una enorme degradación ambiental (Alimonda 2015). Este proceso, que ha persistido en la historia del continente, y que ha ganado fuerza en los últimos treinta años en el marco de una reestructuración económica mundial, ha sido llamado por algunos autores como extractivismo (Gudynas 2015, 2009; Göbel y Ulloa 2014). El extractivismo es la apropiación de la naturaleza a través de la monoproducción y la extracción de grandes volúmenes de recursos naturales generalmente no procesados. Se caracteriza por su multiescalaridad, ya que se crean enclaves productivos en territorios locales, con redes de transporte y energía que conectan el sitio de extracción con puertos, para su exportación a mercados internacionales (Gudynas 2009). El discurso que sustenta este proceso sostiene que los recursos naturales "pertenecen al país" y no a comunidades específicas (como indígenas o campesinos), y que su explotación genera desarrollo y ayuda a reducir la pobreza (Bebbington y Williams 2008). De esta forma, los gobiernos de la región han privilegiado una reestructuración geográfica que ha provocado una acelerada transformación del paisaje, pese a su li- mitada capacidad de distribución de las riquezas y los negativos impactos sociales y ambientales asociados (Bebbington 2013), lo que ha generado la transformación del uso, control y significado de los recursos naturales, afectando el derecho de la población local e incrementando las desigualdades (Göbel \& Ulloa 2014; Bebbington et al. 2008).

Utilizando esta conceptualización, nuestro trabajo se centra en el extractivismo minero, el cual está continuamente presionado por tres grandes elementos: a) la constante exploración y explotación de depósitos para mantener su competitividad, b) el incremento de inversión en tecnología para mantener la producción a bajo costo, y c) la creciente producción de desperdicios (Bridge 2000). El extractivismo minero requiere construir infraestructura para tener acceso a las materias primas más baratas y para acortar la distancia con los mercados (Bunker 2011). Esto significa que se ha ampliado la frontera de recursos a través de la introducción de la minería en lugares donde no se había desarrollado con anterioridad y donde actualmente viven comunidades campesinas e indígenas, lo cual está generando conflictos sociales de importancia (Bebbington et al. 2008). En muchos países de la región, se ha favorecido el control privado sobre la tierra, el agua y otros recursos naturales, lo que ha alterado su uso y su manejo para generar mayores ganancias, lo cual ha ido provocando descontento social dado lo irreversible del daño ambiental (Delgado 2010).

De esta manera, las comunidades campesinas e indígenas, localizadas en aquellas áreas objeto del extractivismo, experimentan la persistencia de órdenes coloniales que afectan sus dinámicas socio-culturales sobre la naturale$z a, y$ los ponen en una condición subalterna con respecto a prácticas y discursos hegemónicos (Alimonda 2011; Escobar 1999; Leff 2006; Martínez-Alier 2004) que terminan por transformar a los territorios donde viven en espacios de "sacrificio" (Svampa 2009). Es decir, los territorios que habitan son transformados completamente para la extracción de recursos a partir de la concentración de la tierra y el agua y su posterior transformación en mercancías, generalmente sin el consentimiento de las comunidades locales, o con mecanismos de participación no vinculante. Así, el daño ecológico no solamente afecta al lugar, sino también al cuerpo, a la identidad, al medio ambiente, a la cultura y a la economía de quien lo habita (Escobar 2011). 
Nuestro aporte a los estudios del extractivismo apuntan a entender el proceso mediante el cual se están ocasionando las contradicciones territoriales entre minería y comunidades indígenas, y cómo esto no necesariamente trae consigo conflictos abiertos contra el Estado y las compañías transnacionales, sino que esquemas de conflictividad latente, que se mueven entre la articulación de identidades indígenas, la reorganización indígena, la lucha por el daño ambiental generado por la minera, acciones legales y de negociación, y multiculturalismo neoliberal. Para ello, creemos necesario introducir el concepto de territorialización, como forma en la cual el extractivismo construye -aunque sea solo de manera provisoria- el que ciertos recursos, en este caso cierto tipo de minerales, territorios y personas con diferentes representaciones y prácticas sociales conflictivas, se mantengan fijas. El concepto de territorialización (Vandergeest y Peluso 1995; Peluso 2005), entendido como prácticas materiales y discursivas del Estado sobre el territorio, ha sido utilizado principalmente por Nancy Peluso, para explicar la construcción del "bosque político" en Estados poscoloniales en Asia. Esta construcción toma forma a través de una serie de discursos, prácticas de conocimiento y relaciones de poder que crean un determinado tipo de paisaje, a través de la movilización de individuos e instituciones, para recolectar, clasificar y controlar características biofísicas y humanas del paisaje, que tiene como fin último manejar, transformar y/o proteger el medio ambiente. La territorialización es un proceso histórico de legitimación cultural y de nuevas formas de poder estatal, de acuerdo con la expansión del capitalismo y en concordancia con la economía global, que gobierna, de manera no coercitiva, qué tipo de personas tiene acceso y control sobre un recurso específico y qué prácticas pueden ser realizadas sobre dicho recurso (Vandergeest y Peluso 1995; Peluso 1995; Vandergeest 1996; Isager y Ivarsson 2010). La territorialización es más fuerte cuando las personas naturalizan los marcos teóricos y prácticas del Estado en sus prácticas cotidianas, muchas veces ignorando o contradiciendo a la gente que vive en los territorios.

Por lo general, la territorialización implica el desplazamiento de población, especialmente "minorías étnicas", dado los altos impactos sobre su medio ambiente (Lestrelin 2011) y la confrontación de estas minorías con nuevos contextos sociales, culturales, económicos y regulatorios. Las comunidades locales contestan y resisten las prácticas estatales, a través de la persistencia o la reelaboración de interpretaciones del territorio, mostrando usos locales de la tierra y prácticas culturales cotidianas, sustentados en derechos basados en las costumbres (Peluso 1995, 2005; Isager y Ivarsson 2010). Esta contraterritorialización no necesariamente está asociada a grandes movimientos sociales, sino que con actos cotidianos de resistencia (Lestrelin 2011).

Dentro de esta conceptualización de construcción de consensos sobre la explotación de recursos promovidos por el Estado, a través de instituciones, leyes, discursos y prácticas cotidianas no coercitivas, es desde donde creemos que es importante entender el caso del extractivismo minero en América Latina. En esta región, desde la década de los noventa la inversión en minería ha crecido exponencialmente, multiplicándose hasta en un $400 \%$, lo que representa un $30 \%$ de la inversión mundial (Bridge 1999, 2004). En este período, han arribado compañías transnacionales como Barrick Gold, Falcon Bridge, Yamana Gold, Phelps Dodge, Río Tinto, BHP-Billiton, Sumitomo, Anglo American y Xstrata Copper (Delgado 2010), lo que en países como Chile ha venido acompañado de la concesión y privatización de grandes extensiones de tierra para explotación minera.

En nuestra perspectiva, el extractivismo debe ser entendido dentro de un proyecto político y económico democrático (aunque en el caso de Chile profundamente atado a la anterior dictadura), el cual, a través de marcos legales de corte neoliberal en inversiones extranjeras, agua, minería y energía, generaron que ciertas prácticas socioambientales hayan sido internalizadas. Sin embargo, la dramática transformación de los paisajes de extracción, mostraron la forma en la cual se está ejecutando una modernización con degradación socioambiental, en la cual el territorio ha sido y está siendo ordenado y planificado por actores traslocados, y donde la participación ciudadana está limitada. Este hecho ha contribuido a desarrollar luchas sociales por la defensa de derechos territoriales y culturales colectivos (Svampa 2009, 2011), muchas de ellas levantadas por poblaciones indígenas, especialmente en la región andina de América. 


\section{* El fenómeno de la articulación indígena}

En muchos países del mundo, se ha venido desarrollando un proceso de articulación indígena (Clifford 2013; Li 2000) que ha traído consigo la negociación y contestación sobre las formas en las cuales los Estados poscoloniales han producido y construido el territorio. Existe un contexto internacional de reconocimiento y revitalización de los pueblos indígenas, que se inicia vinculado a la discusión de postguerra sobre derechos humanos, y que comienza a tomar formar con el Convenio 107 de la Organización Internacional del Trabajo de 1957 (no ratificado por Chile). Ronald Niezen (2002) señala que el resurgimiento indígena global no puede ser entendido sin referencias a las tecnologías, poder y legitimidad del Estado, y como reacción a la compensación sobre las pérdidas, sufrimiento y las faltas a la honorabilidad (Niezen 2002), que ha generado que ciertos grupos hayan sido marginalizados y minorizados por la extracción de recursos y la modernización económica. En el caso de América Latina, el fenómeno ha sido denominado "emergencia indígena" (Bengoa et al. 2012), que comenzó a surgir desde los setenta, a partir de diferentes organizaciones que tuvieron diversos orígenes, estrategias e intereses políticos, identidades y preocupaciones territoriales. Los movimientos indígenas han basado sus demandas en el derecho a la autorrepresentación y soberanía sobre sus territorios y el ejercicio de sus identidades culturales, definiéndose a sí mismos como pueblos indígenas, más que como minorías étnicas o raciales dentro de una sociedad dominante (Ulloa 2005). Esta "emergencia" se intensificó en América Latina, entre otros factores, como reacción a la conmemoración de los quinientos años del descubrimiento de América en 1992.

La autoidentificación indígena no es un fenómeno natural o inevitable, pero tampoco es un fenómeno meramente inventado, adoptado o impuesto (Li 2000). Por el contrario, es una articulación cultural y política de discursos y fuerzas sociales (Hall y Du Gay 1996), que tienen prácticas históricas, representaciones, y significados que han estado en conflicto latente y que confluyen en la conformación de identidades colectivas de manera contingente o provisional. La articulación es un posicionamiento (Hall 1990) táctico, y se puede volver explícito y transformativo en tiempos de movilización y politización (Li 2000). De acuerdo a James Clifford (2013), la articulación indígena se mueve dentro de espacios hegemónicos y contra-hegemónicos (derechos humanos, ONG, programas multiculturales), donde la resistencia no implica el rechazo total, sino que táctico, en alianza con otros grupos para maniobrar.

En esta perspectiva, la identidad indígena no es algo dado, sino que producido. Es un ensamblaje que emerge de la interacción entre partes, donde las instituciones cumplen un rol central, materializando y haciendo reconocibles cualidades específicas, capacidades y posibilidades (Sawyer y Terence Gomez 2012). Esta identidad indígena se articula en el contexto de proyectos etnoterritoriales que ocupan un esencialismo estratégico (Perrault y Green 2013; Prieto 2016), para demandas históricas sobre la forma en la cual se ha territorializado el Estado. En estas demandas, las diferencias lingüísticas, culturales, y la localización rural son indicadores claves de identidad indígena. De acuerdo con Niezen (2002) la identidad indígena se ha fortalecido a partir de una historia compartida de desposesión, junto con ciertas formas de economía de subsistencia que aún sobreviven, y que se desarrollan en un territorio cuya data es anterior a la llegada de colonos y geomensores. Al mismo tiempo, comparten un sistema espiritual que data desde antes de la llegada de los misioneros, y un idioma o lengua que expresa "todo lo que es importante y distintivo sobre su lugar en el universo" (Niezen 2002). De esta manera, para los pueblos indígenas, la subsistencia en su tierra es una de las más importantes fuentes de autonomía y poder, y constituye la ideología indigenista (Perrault 2012). Desde aquí se legitiman sus reclamos por tierra, resaltando o incluso exagerando, valores tradicionales como la reciprocidad, la vida en comunidad y el respeto por el medio ambiente (Ulloa 2005).

La producción de la identidad indígena, en el contexto internacional, debe ser entendida desde Naciones Unidas (1986), la que establece la continuidad histórica de aquellos que viven en territorios donde había población antes de la invasión europea. En la actualidad, estos grupos no pertenecen a los sectores dominantes dentro de la sociedad, y tienen sistemas sociales, culturales y políticos distintos, así como también lenguaje, cultura y creencias diferentes. Una segunda fuente de producción de identidad indígena viene del Convenio $\mathrm{N}^{\circ} 169$ de la Organización Internacional de Trabajo (1989), ra- 
tificado por Chile en 2008, donde se reconoce como población indígena a aquella que tiene continuidad histórica, cultura y formas de vida diferentes a la población nacional y que posee sus propias organizaciones sociales e instituciones políticas.

Nuestro trabajo contribuye a entender los procesos de articulación identitaria desarrollados desde espacios urbanos, especialmente de la población aymara en Chile, en el contexto de la expansión minera. En este sentido, viene a complementar el trabajo de Tom Perrault (2012), quien ha analizado la situación de aymaras y quechuas urbanos, pero en Bolivia, a partir de la indigeneidad, como concepto que trasciende la división urbano/rural y etnia/clase. Nuestro trabajo se suma también al análisis que Manuel Prieto ha hecho sobre el proceso de articulación indígena en relación con las tradiciones y las costumbres dentro del contexto urbano y de la gobernanza neoliberal del agua (Prieto 2016) y procesos de colectivización de derechos por parte de comunidades atacameñas en el norte de Chile (Prieto 2014). Esta investigación avanza en entender el caso chileno, en el que es posible identificar una creciente concentración de población indígena residente en zonas urbanas, que comenzó desde los años noventa a desarrollar un proceso de articulación identitaria, que ha tenido en la demanda de tierras y agua una de sus principales reivindicaciones. Son la institucionalidad indígena, la persistencia de prácticas andinas de la población recientemente urbanizada, y las empresas mineras y sus políticas para evitar los conflictos socioambientales, las que han contribuido a la conformación de comunidades aymara y quechua.

\section{$*$ Metodología}

El objetivo de esta investigación es estudiar las transformaciones y contradicciones socio-territoriales que se están desarrollando en el norte de Chile, específicamente en la región de Tarapacá, en el contexto de la expansión minera y de la activación de un proceso de reivindicación indígena desde los años noventa. Nuestros objetivos específicos han sido indagar sobre la territorialización de la inversión minera en la región, la declaración de áreas de protección del medio ambiente y la cultura, y del creciente proceso de reconocimiento de territorios indígena por parte del Estado chileno. De la misma manera, nos ha interesado conocer la estructura de la población que se reconoce como indígena en el norte de Chile, y comprender lo que ha significado para sus dirigentes el proceso de transformación minera y la articulación identitaria.

Esta investigación presenta un método mixto en la recolección y análisis de datos. Primero, se recurrió a fuentes secundarias para estudiar el proceso de organización de las comunidades aymaras, quechuas y atacameñas y el proceso de expansión minera. En segundo lugar, se ha utilizado información georreferenciada proveniente de instituciones como Conadi, Sernageomin y la Biblioteca del Congreso Nacional para poder caracterizar territorialmente a la región. Posteriormente, se recurrió a información secundaria, sobre todo a la serie histórica de la encuesta de Caracterización Socioeconómica de Chile (Casen) enfocada en la población indígena. Por último, se utilizó información primaria a partir de treinta entrevistas a dirigentes aymaras y quechuas de la región de Tarapacá y a informantes claves de servicios públicos, ONG y consultoras realizadas durante el 2014 y el 2015. Nuestra investigación ha asegurado el anonimato de los participantes. Solo una parte de los entrevistados estuvo dispuesta a darnos su consentimiento informado de manera escrita, mientras el resto lo dio de manera verbal. Este hecho a nuestro juicio es significativo, puesto que da cuenta de las desconfianzas existentes en la región a la hora de hablar de los impactos de la minería sobre las comunidades indígenas y el medio ambiente.

Para observar el comportamiento del cuerpo de agua de Lagunillas, ${ }^{4}$ se realizó una digitalización en base a percepción remota a seis imágenes satelitales, una landsat 1 con fecha 24 de marzo de 1973, una landsat 5 con fecha 2 de agosto de 1987, una Google Earth con fecha 13 de septiembre de 2004 , dos landsat 7 con fecha 16 de abril de 2006 y 24 de abril de 2009 y una Terra Server con fecha 2 de agosto de 2014, con el fin de analizar la variación histórica en la superficie del cuerpo de agua. Este análisis se contrastó con información de precipitación para establecer si existe correlación entre el tamaño del cuerpo de agua y el agua caída. Los datos pluviométricos de la estación Lagunillas (ID M_OO2_AJ) fueron extraídos de la página web de

4 Según el estudio de censos de avifauna de la región de Tarapacá (SAG, 2013), el tamaño y la forma del cuerpo de agua de Lagunillas es variable en distintas épocas del año según las condiciones climáticas imperantes. 
los datos hidrometereológicos de la Dirección General de Agua (DGA), que registra información desde el año 1982.

\section{* La territorialización minera y el proble- MA DEL AGUA EN El NORTE DE CHILE}

De acuerdo a Vandergeest \& Peluso (1995), la territorialización es una forma inestable de despliegue del Estado en el territorio, que ocurre no solamente a través de la instalación de instituciones, sino que también en la aplicación de ciertas tecnologías (por ejemplo, mapeos y zonificaciones) y la creación de ciertos tipos de derecho que regulan el acceso a determinados recursos por determinados sectores de la población. Inicialmente, la territorialización del Estado puede efectuarse a través medios coercitivos para expropiar y controlar recursos, legitimar fronteras y organizar a la población, pero tiende a moverse a medios no coercitivos cuando las poblaciones internalizan las formas en las cuales el Estado controla sus actividades y su dominio y acceso de recursos. En el caso de Chile, la principal forma en la cual el Estado consolidó su presencia en los territorios anexados con posterioridad a la Guerra del Pacífico, fue a través de la especialización del norte en producción minera, especialmente de salitre.

La territorialización del Estado significó el fortalecimiento de las ciudades puerto (Arica, Iquique y Antofagasta) y la transformación de las salitreras en agencias de colonización. Las salitreras no solamente fueron enclaves que concentraron recursos naturales (tierra y agua) y el mercado laboral, sino que al mismo tiempo impusieron un estilo de vida urbano y la proletarización de la población andina (Cariola y Sunkel 1982; Gonzáles 2011; Blázquez 1999) que contribuyeron a forjar una "cultura pampina". El uso y la propiedad del agua del altiplano y la precordillera se orientaron a la industrialización del salitre y al proceso de urbanización (Madaleno 2004), provocando el despojo de recursos hídricos de las comunidades andinas. La relación entre la población indígena y la sociedad chilena fue mediada por las salitreras, a través de la especialización de la población indígena como abastecedores de productos y mano de obra, lo que modificó el relativo aislamiento en el cual se encontraban (Castro 1997; Van Kessel 1980). Conjuntamente, se inició un agresivo proceso de asimilación cultural llamado chilenización, a través de la instalación de instituciones públicas, como la escue-

la, para adoctrinar a la población aymara, quechua y atacameña en la nueva cultura dominante chilena (Gonzáles 2002; Van Kessel 2003; Aylwin et al. 2013).

Sin embargo, el ciclo de expansión del salitre terminó abruptamente en el período de entreguerras, generando una severa crisis social. Los movimientos obreros en las salitreras fueron particularmente fuertes, lo que provocó una violenta represión por parte del Estado a través del Ejército, afectando también a la población indígena. Una parte de ella se replegó hacia sus localidades de origen en los Andes, mientras otros "bajaron" a las ciudades puerto, buscando mercancías, el acceso al mercado del trabajo y la educación (Castro y Bahamondes 1987; Grebe 1998). A partir de la segunda mitad del siglo XX, se registró un importante proceso de migración de la población indígena hacia zonas urbanas, impulsado por la consolidación minera del norte de Chile (cobre, plata, litio, bórax y hierro) (Gundermann y Gonzáles 2008), y el impacto de la minería sobre la disponibilidad y calidad del agua, lo que ha afectado a la agricultura de la población andina (Carrasco y Fernández 2009; Madaleno 2004).

Una segunda oleada de territorialización minera en el norte de Chile fue a través de la industria del cobre. Durante la primera mitad del siglo XX, el Estado entregó concesiones mineras a compañías norteamericanas, cuyo máximo ejemplo fue Chuquicamata, que se transformó en el símbolo del progreso que generaba el cobre para Chile. Sin embargo, la presencia estatal en el Norte se volvió intensiva desde 1966, cuando el gobierno de Eduardo Frei Montalva inició la compra de los yacimientos mineros de cobre para ponerlos en manos del Estado, mediante la chilenización del cobre. Esto significó la incorporación del cobre como una de las principales fuentes de financiamiento de las políticas sociales, discurso que perdura hasta el día de hoy en la sociedad chilena. En 1971, y con el apoyo unánime del Congreso Nacional, Salvador Allende promulgó la nacionalización y estatización de la gran minería del cobre, fortaleciendo su importancia para el futuro del país. La presencia estatal en la producción no sufrió cambios en el periodo de dictadura militar de Pinochet: en 1976 se fundó la Corporación Nacional del Cobre (Codelco), la cual se transformó con los años no solamente en la empresa que contribuye más a la economía chilena, sino también en una de las mayores productoras de cobre en el mundo. Actualmente, más del $90 \%$ de la producción del país está en manos

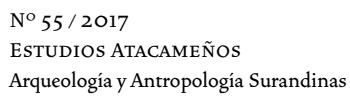


de 17 compañías mineras privadas, entre ellas BHP Billiton, Anglo American, Río Tinto y Teck. Sin embargo, la estatal Codelco, con sus ocho divisiones, representaba el $32 \%$ de la producción de cobre de Chile el 2014. ${ }^{5}$

La territorialización minera y el boom cuprífero en el norte de Chile son consecuencia de la reestructuración mundial de la economía en términos tecnológicos, organizacionales y geográficos (Bridge 2000, 2004). A escala nacional, el extractivismo minero fue planificado por el Estado chileno, y alcanzó una mayor fuerza a través de las políticas neoliberales y las reformas profundas a las inversiones extranjeras (1974) a la tierra (1979), al agua (1981) y a la minería (1983). Esto significó la firma de acuerdos entre el Estado y compañías transnacionales, para traspasar los yacimientos anteriormente nacionalizados a manos de privados. Por ejemplo, en la región de Tarapacá, en el año 1977 comenzó la explotación del yacimiento Quebrada Blanca por capitales transnacionales, entre ellos Falconbridge y Canadian Superior Oil. En 1979 terminaron las exploraciones del yacimiento Cerro Colorado por las empresas Nippon Mining y Mining Development. Por su parte la Compañía Doña Inés de Collahuasi comenzó su reorganización en 1975, de la mano de Superior Oil y Falconbrige, y realizó variados estudios durante las décadas de 1980-90 (Millán 2006; Meza 1983). De esta forma, el cobre, en cuanto mineral necesario para el desarrollo del país, pasó de manos estatales a manos transnacionales, y el norte de Chile, en cuanto territorio, pasó a constituir la palanca del crecimiento económico, especialmente las regiones de Antofagasta y Tarapacá.

La expansión minera no fue la única forma de territorialización estatal. Desde fines de la década de 1970, el sector andino del norte comenzó a especializarse en conservación de la naturaleza. Esto se consolidó a partir de 1984 con la creación del Sistema Nacional de Áreas Silvestres Protegidas del Estado, SNASPE. De esta manera, vastos territorios con escaza población fueron transformados en áreas de conservación que aseguran la presencia estatal y limitan el acceso y uso de dichos territorios, especialmente de los grupos indígenas que históricamente habían recolectado leña y ocupado el sistema de humedales para la ganadería.

5 Publicado en www.consejominero.cl el 2015
A partir de los noventa, con la vuelta de la democracia, y luego de una reorganización de la propiedad, los yacimientos Cerro Colorado (BHP Billiton), Quebrada Blanca (Teck) y Doña Inés de Collahuasi (Anglo American) comenzaron a funcionar de forma intensiva en la región de Tarapacá. Por ejemplo, Collahuasi pasó a producir el $3 \%$ de la producción mundial de cobre. Las exportaciones desde la región de Tarapacá se multiplicaron desde $2 \%$ en el período 1990-1992 a 7\% a nivel nacional en el período 2006-2008. De la misma manera, se pasó de concentrar el 1,3\% de la inversión extranjera directa en el período 1974-1989, a 5,3\% en el período 1990-1998 (CIPTAR, 2012). Según la Comisión Chilena de Cobre (Cochilco), la región de Tarapacá aportó con un 10\% al PIB nacional en 2013. En términos del PIB regional, la minería aportó un $52,5 \%$ en 2008 , pero disminuyó a $46,7 \%$ en 2011. En términos de su aporte al empleo regional de Tarapacá, éste creció de 6,9\% el 2010 a 8,9\% en 2011 y $11 \%$ el 2013 (Cochilco 2013). En tanto, el agua para sustentar este boom ha provenido principalmente de fuentes subterráneas $(1.153 \mathrm{l} / \mathrm{s})$ y en mucho menor medida de fuentes superficiales $(104 \mathrm{l} / \mathrm{s})$ dada la híper aridez del territorio (Cochilco, 2015). La concentración del agua para los procesos mineros del cobre, amparada primero en la estatización y luego en la privatización, fue generando una importante contradicción entre minería y comunidades indígenas.

La presión sobre los recursos hídricos localizados en territorio donde viven comunidades aymaras, quechuas y atacameñas, por parte de las mineras en el norte de Chile, generó que la Ley Indígena de 1993 incorporara referencias específicas para el territorio y el agua de las poblaciones indígena del desierto de Atacama. De esta manera, el agua, que había sido privatizada en 1981, se abrió a un nuevo régimen legal que reconoció que para ciertas poblaciones en localizaciones específicas existen derechos y usos comunitarios del recurso:

Se deberá proteger especialmente las aguas de las comunidades Aimaras y Atacameñas. Serán considerados bienes de propiedad y uso de la Comunidad Indígena establecida por esta ley, las aguas que se encuentren en los terrenos de la comunidad, tales como los ríos, canales, acequias y vertientes, sin perjuicio de los derechos que terceros hayan inscrito de conformidad al Código General de Aguas (Ley 19.253, Artículo 64) 
Por su parte, el informe de la Comisión de Verdad Histórica y Nuevo Trato con los Pueblo Indígenas (2009), impulsado por el Estado chileno, señaló explícitamente que las comunidades aymara, quechua y atacameña han sido enormemente afectadas por el Código de Agua de 1981, que permitió la privatización, y que anuló los usos históricos del recurso para reorientarlos hacia el mercado buscando maximizar su uso y precio (Prieto y Bauer 2012). La literatura especializada registra varios casos en que el extractivismo minero ha afectado el agua de las comunidades indígenas en el norte de Chile: la compra de derechos de agua superficiales a precios más bajos que los de mercado en Quillahua (Budds 2007), la inscripción de solo un número reducido de derechos de agua superficial de carácter individual supuestamente para que los comuneros no tuvieran que pagar posibles impuestos o con el afán de "protegerlos" de grandes intereses económicos como en Chiu Chiu y Lasana (Molina 2012; Prieto 2014), la exploración y extracción de agua subterránea sin consentimiento de las comunidades, como el caso de Pampa Lagunilla (Van Kessel 1985; Larraín y Poo 2010; Salinas 2012), la captación de aguas superficiales mediante tubos y pozos, principalmente en el río Loa (Yáñez y Molina 2011), y la contaminación del agua que generan los relaves mineros emplazados a escasos kilómetros de las comunidades, como en Chiu Chiu y Quillagua (Yáñez y Molina 2008). ${ }^{6}$ Estas contradicciones socioterritoriales, que representan la larga historia de despojo, habrían fortalecido el proceso de autoidentificación indígena. La Ley Indígena, a partir de los cambios introducidos en el contexto de reconocimiento a los denominados pueblos originarios, ha generado importantes cambios. De esta forma, la identidad indígena no debe ser pensada como algo fijo o dado, sino como históricamente contingente, contestada, negociada y politizada.

\section{* La articulación identitaria de los ayma-}

\section{RAS EN EL NORTE DE CHILE}

Como lo señala Manuel Prieto, algunos autores que han analizado políticas identitarias indígenas en Chile han ocupado conceptos como "re-etnificación" para referirse a un proceso de recuperación de la identidad étnica (Van Kessel 2003; Rivera 1997), donde la población

6 Para un análisis detallado y sistemático del proceso de aplicación del Código de Aguas en territorio atacameño ver las tesis de doctorado de Manuel Prieto (2014) y Francisco Molina (2014). indígena estaría retornando o recuperando algo que se perdió en el transcurso del tiempo o en un pasado esencial (Prieto 2014). Por el contrario, nosotros ocupamos el concepto de "articulación" porque queremos mostrar que es un fenómeno actual, con diferentes rutas, muchas veces emergiendo de forma contradictoria, que produce subjetividades de manera más inestable y que actúan políticamente. En el caso de Chile, la principal fuente de institucionalización de lo que hoy entendemos como pueblos indígenas es la Ley Indígena (1993), la cual reconoció en esta calidad a aquellos que descienden de los ocupantes del territorio nacional desde la época precolombina y que conservan manifestaciones étnicas y culturales, "siendo para ellos la tierra el fundamento principal de su existencia y cultura" (Ley 19.253, artículo 1). La Ley Indígena y la conformación de la Corporación Nacional de Desarrollo Indígena (Conadi) fueron las formas con las cuales el Estado reaccionó a un escenario marcado por una acelerada urbanización, el mayor acceso a la educación de poblaciones que habían estado históricamente excluidas, los impactos del extractivismo neoliberal sobre los territorios indígenas, principalmente en minería, industria forestal e hidroeléctricas, y la capacidad de la población indígena de articularse en una serie de organizaciones formales e informales de variado tipo, que comenzaron a conectar los territorios ancestrales con los espacios urbanos.

Sin embargo, el territorio conocido hoy como Norte Grande de Chile tiene una larga historia de ocupación humana, que constituye la base de los que hoy se denominan pueblos indígenas. Dada la extrema condición climática y la topografía del desierto, el agua siempre ha sido un recurso crítico para estos habitantes, jugando un rol clave en términos materiales, sociales y cosmológicos (Castro et al. 1991). Por cientos de años, el espacio andino ha estado socialmente organizado a través de pisos ecológicos (Murra 1975; Hidalgo 2004), donde la tierra, el agua y la sociedad han estado íntimamente relacionadas, dependiendo fuertemente de las lluvias y del agua subterránea. Sobre los $3.800 \mathrm{~m}$ de altitud, las comunidades aymaras desarrollaron la ganadería en humedales altoandinos, mientras que en la precordillera se desarrolló la agricultura, muchas veces a través de complejos sistemas de irrigación. Entre los 3.000 y $2.000 \mathrm{~m}$ de altitud, la agricultura ha sido practicada en las quebradas usando la limitada agua de los ríos y en los oasis, donde afloran 
vertientes. Desde el siglo XIX, con el arribo del capitalismo, y por sobre todo después de la guerra entre La Confederación Perú-Bolivia y Chile, que dio por ganador a este último, el agua fue concentrada por el Estado para abastecer a las ciudades y a las mineras.

En Chile, se incluyó por primera vez una pregunta sobre autoadscripción en el Censo 1992: Si usted es chileno, ¿Se considera perteneciente a alguna de las siguientes culturas? Las opciones de respuesta sobre autoidentificación fueron: aymara, rapanui y mapuche (998.385 personas se autoidentificaron como indígenas). Por su parte, en el Censo 2002, la pregunta fue orientada a la pertenencia: ¿Pertenece usted a alguno de los siguientes pueblos originarios o indigenas? Se sumaron a las opciones de respuesta atacameño, quechua, colla, kawésqar y yagán, llegando a reconocerse ocho pueblos indígenas (692.192 personas dicen pertenecer a uno de los pueblos indígenas señalados). En el Censo 2012, se preguntó por autoidentificación y pertenencia: ¿Se considera perteneciente a algún pueblo indígena? (con opción sí o no). En segundo lugar, se preguntó: ¿A cuál pertenece? En las opciones de respuesta apareció likan antai en reemplazo de atacameño y se sumó además a los diaguitas (1.807.443 personas declararon pertenecer a un pueblo indígena). Finalmente, se preguntó: ¿En qué idiomas puede tener una conversación? Las opciones de respuesta fueron: español, mapudungun, aymara, quechua, rapanui e inglés.? Los datos del censo no permiten una comparación, porque las preguntas de 1992, 2002 y 2012 no miden lo mismo. Adicionalmente a los pueblos indígenas identificados a través del censo, un estudio de la Subsecretaría de Desarrollo Regional (SUBDERE, 2010), señaló que en la región de Tarapacá también se ha registrado un incipiente proceso de organización de urus y chipayas.

De esta manera, en el Norte Grande de Chile, a la presencia de los aymaras y atacameños, hay que sumar el reciente proceso de articulación quechua y de otros grupos, entre ellos los changos, y también el esfuerzo que están haciendo los afrodescendientes. En alguna de nuestras entrevistas se nos señaló que parte de esta articulación se estaría generando en las zonas urbanas, y que tendría como fin el acceso a beneficios que pueden conseguirse

7 Los datos del Censo 2012 no pueden ser utilizados dado el cuestionamiento del Centro Latinoamericano y Caribeño de Demografía (Celade) por no cumplir los estándares. por parte de Conadi, como también de las mineras. Sin embargo, y contrario a esta opinión, un líder aymara de la zona andina nos planteó que este proceso de activación de identidades es propio de un lugar que siempre ha estado poblado por una diversidad de grupos indígenas, los cuales no habían podido expresar anteriormente sus diferencias con la cultura dominante:

yo no creo que la organización de otros pueblos [indígenas] sea mala. Si usted va a Iquique tú encuentras croatas, ingleses, chilenos, argentinos, peruanos, bolivianos... acá [hacia el interior del territorio] siempre ha sido lo mismo. Siempre ha habido aymaras, quechuas, urus. De hecho, por acá viven unos urus. Siempre han vivido por acá" (dirigente indígena, aymara, hombre de la tercera edad, octubre de 2014).

Dentro de este proceso de articulación, la inscripción de organizaciones en el marco de la Ley Indígena tuvo un ritmo acelerado. Según Gundermann y Vergara (2009), las organizaciones andinas se han prolongado hacia las zonas urbanas y han surgido de la necesidad de reconstruir relaciones sociales en la ciudad, ante la pérdida de recursos considerados comunes o colectivos. En este contexto surgen las comunidades indígenas modernas, donde el concepto de "comunidad" es algo más inestable, que mezcla lo tradicional con lo moderno y lo urbano con lo rural, y donde los poblados andinos tienen una función de repliegue frente a los vaivenes del mercado laboral y el envejecimiento de la fuerza de trabajo (Gundermann y Vergara 2009; Gundermann y González 2008; Subdere 2010). Las comunidades indígenas de Tarapacá, tienen un carácter genealógico, histórico y geográfico, asociado a un poblado o caserío. En ellas están inscritos los residentes de los pueblos del interior, y la parte de la familia que emigró hacia las zonas urbanas. Las comunidades son organizaciones políticas, y por tanto, sometidas a las mismas dinámicas que otras organizaciones del Chile posdictatorial, que ensayan prácticas democráticas, con distintos niveles de participación, que corresponden a redes de poder local e incluso regional, y que pueden llegar a establecer distintos tipos de relaciones con el Estado y las compañías mineras. Sus intereses varían entre elementos políticos, de clase, étnicos, de género y de valoración del ambiente, $y$ deben ser entendidas como insertas en las transformaciones socioambientales históricas por las que ha atravesado el Norte de Chile.

Según el catastro de Conadi del año 2015, en la región 


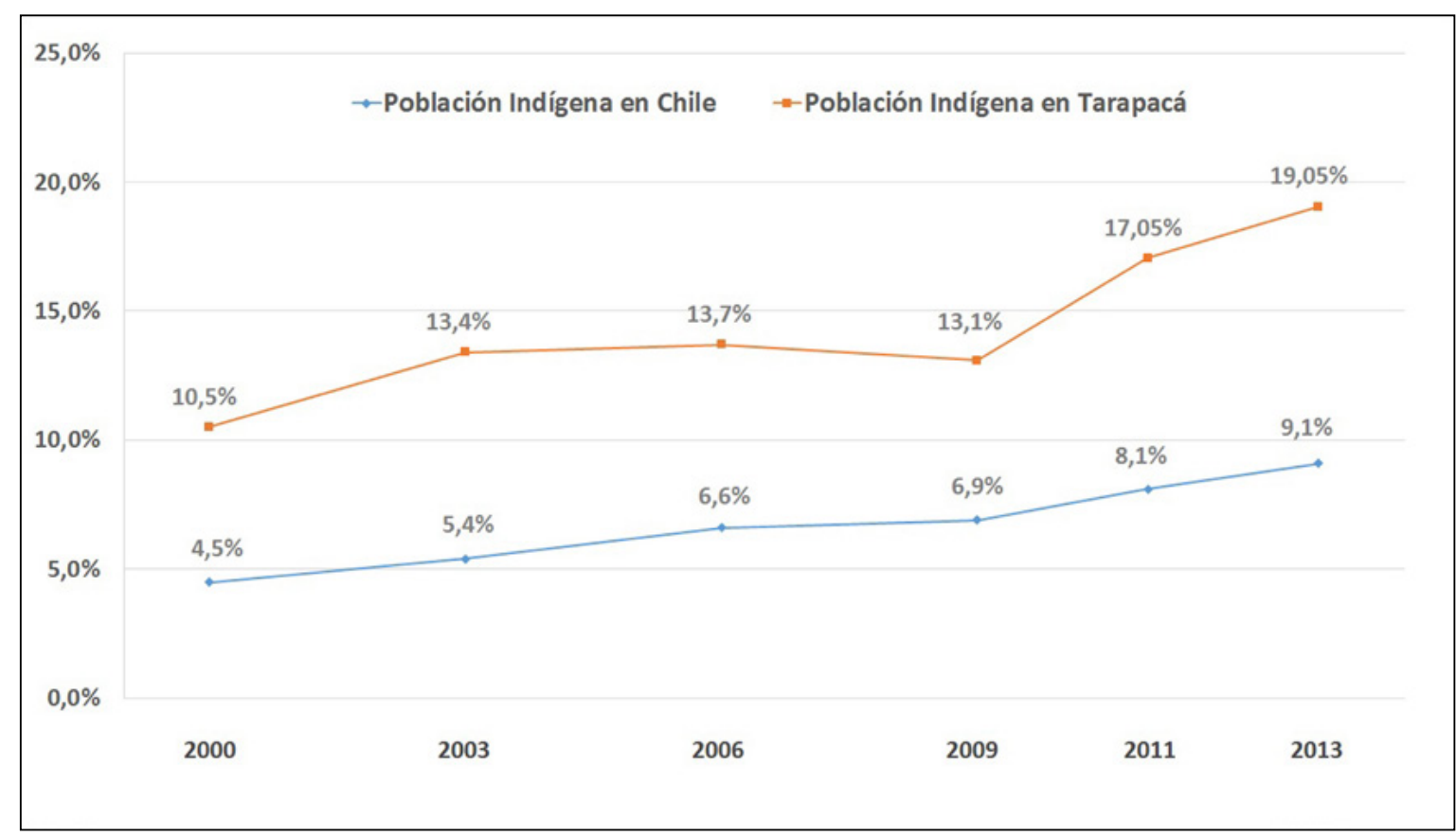

Figura 1. Evolución de la población indígena en la región de Tarapacá, 2000-2013.

Fuente: Elaboración propia en base a Encuesta Casen 2000-2013

de Tarapacá se contabilizan 268 asociaciones indígenas y 106 comunidades indígenas. La razón de lo anterior, según las entrevistas que hemos realizado, es que los cambios legales le permitieron a la población indígena poder reconocerse: "Antes nos daba miedo decir que somos una comunidad" (dirigente indígena, aymara, mujer de tercera edad, noviembre de 2014). Esto representa sin duda un gran avance en la lucha de los pueblos indígenas. Como lo menciona con orgullo una de nuestras entrevistadas: "Si, yo soy indígena. Yo soy de esta comunidad" (dirigente indígena, aymara, mujer de la tercera edad, noviembre de 2014). De esta forma, en el área rural se concentran las comunidades, que están compuestas por un reducido número de miembros que aún viven en el poblado de origen, mientras el grueso de ellos reside en las ciudades.

Junto con la formalización y el aumento de las organizaciones indígenas, comenzó a crecer el número de personas que se adscriben a los pueblos indígenas. La encuesta Casen pregunta: En Chile, la ley reconoce la existencia de 9 pueblos indígenas. iPertenece usted o es descendiente de alouno de ellos? Para la región de Tarapacá los resultados son los observados en la Figura 1.
Los datos de la Figura 1 muestran un sostenido incremento de la población que se auto-identifica como indígena en la región de Tarapacá. Además, el porcentaje de población indígena que vive en zonas urbanas alcanzó el $87,6 \%$ en 2013 , mientras que se observa una disminución de la población indígena rural, que descendió de 15,5\% el año 2006 a 12,3\% en 2013 . En relación a la población aymara y quechua que vive en la región, los datos que arroja el análisis histórico de Casen muestran un aumento considerable. El año $2000^{8}$ la población aymara correspondía a un $8,3 \%$ de la población total de Tarapacá, cifra que representa un aproximado de 19.760 personas. Trece años después, quienes se declaran aymaras ascienden a 37.307 personas, existiendo un aumento de $47,1 \%$. De la misma manera, existe un crecimiento de la población quechua en la región de Tarapacá, pasando de 337 personas en el 2000 a 5.623 adscritos el 2013. Cabe destacar que la población regional ha crecido en un $25,2 \%$ entre el 2000 y 2013 , y que parte de la pobla-

8 Para realizar el cálculo de población correspondiente a la actual división política administrativa de La región de Tarapacá en el año 2000 y 2003 en base a Casen, se consideró solo aquellas comunas pertenecientes a la región creada en 2007. Para el año 2006 la base de datos Casen posee una variable con la nueva división. 
ción que se autoidentifica como aymara y quechua proviene de países fronterizos. Para el 2013, 2.365 de los encuestados que se autoidentificaron como aymaras eran extranjeros, mientras que en los quechuas la cifra alcanzó los 1.639 .

Por último, desde 1995, y a través de Conadi, se crearon las Áreas de Desarrollo Indígena (ADI), entendidas como unidades territoriales donde el Estado focaliza recursos para las comunidades. Los criterios para la designación de un ADI se basaron en la ocupación ancestral del territorio, alta densidad de población indígena, homogeneidad ecológica y dependencia de recursos naturales como la tierra, el agua, flora y fauna. Según los documentos oficiales, las ADI tienen como objetivo la superación de la pobreza, el rescate de la cultura y acoger las demandas de tierras, aguas y organización. En el Norte Grande se han constituido las siguientes ADI: Alto Andino en la región de Arica y Parinacota (2004), Jiwasa Oraje (2001) en Tarapacá, y Atacama La Grande (1997) y Alto Loa (2003) en la región de Antofagasta.

De esta forma, una nueva geografía indígena comenzó a surgir. Por una parte, han aumentado el número de comunidades y asociaciones indígenas reconocidas por el Estado que conectan el territorio originario del altiplano y la precordillera con la población indígena que vive en zonas urbanas, como Iquique y Alto Hospicio. Por otra parte, el Estado reconoce a las comunidades como organizaciones que tienen presencia territorial, y que demandan el control de la tierra y el agua, fuertemente presionadas por el crecimiento urbano y el boom minero. Por último, se crean las ADI como forma de reconocer un territorio para la población indígena, donde se focalizan recursos para mejorar la calidad de vida de las comunidades y al mismo tiempo la sustentabilidad del territorio.

Como lo ilustra la Figura 2, en la sección precordillerana comienza a agravarse la coexistencia de comunidades, yacimientos mineros, áreas de desarrollo indígena (ADI), y áreas silvestres protegidas del Estado (SNASPE). La Ley 19.300, sobre Bases Generales del Medio Ambiente (1994) y sus posteriores modificaciones, entre ellas el Decreto 66 (2013) que regula la Consulta Indígena para aquellos proyectos de inversión que se localicen en los territorios reconocidos como de uso estos pueblos. Este proceso legal contribuyó a hacer visible la ocupa- ción territorial de los diversos grupos indígenas. En el procedimiento de Evaluación de Impacto Ambiental, las empresas deben declarar el impacto que generan o generarán sobre el medio humano, con especial énfasis en la presencia de comunidades indígenas localizadas en las áreas de extracción. Sin embargo, la consulta indígena no es vinculante. Como lo ilustra la Figura 2, en la región de Tarapacá se produce una importante colisión territorial, dado que la Compañía Minera Cerro Colorado se localiza dentro del ADI Jiwasa Oraje, donde habitan comunidades aymaras y quechuas, y donde también existen áreas de protección de la naturaleza, como el Salar del Huasco (recientemente desafectado). Es en este escenario actual donde ha ocurrido uno de los eventos más significativos para entender la conflictividad de la minería en Chile en tierras indígenas: el caso de Lagunillas.

En este proceso de articulación identitaria en contexto de extractivismo minero, la población indígena comenzó a mostrar un repertorio de acciones (Prieto 2014) que van desde la certificación del ser indígena frente al Estado (Gavilán y Lagos 2014), la participación en políticas neoliberales multiculturales (Boccara y Bolados 2008), el desarrollo de acciones cotidianas por demandas de reconocimiento y otras problemáticas (Gundermann 2004; Gundermann y Vergara 2009; Zapata 2007) y la defensa del territorio frente a grandes inversiones, especialmente por daño ambiental (Carrasco y Fernández 2009).

\section{* El caso de pampa lagunillas 9}

Tal vez uno de los casos paradigmáticos dentro de los conflictos socioambientales que involucran a comunidades indígenas y la gran minería privada en Chile, es el de la Compañía Minera Cerro Colorado (CMCC) y la comunidad aymara de Cancosa, específicamente en lo que refiere a recursos hídricos y degradación medioambiental. Este conflicto se ha desarrollado en el contexto de las dinámicas andinas de la segunda mitad del siglo XX, los cambios introducidos por las políticas neoliberales sobre la tierra y el agua que favorecieron a la industria minera, y el proceso de articulación de identidad indígena, donde se involucra la parte de la comunidad que todavía reside

9 Los datos de esta sección provienen de entrevistas realizadas a dirigentes de comunidades aymaras y quechuas, personal de servicios públicos, ONG y consultores. El equipo investigador se comprometió a garantizar el anonimato de las fuentes. 


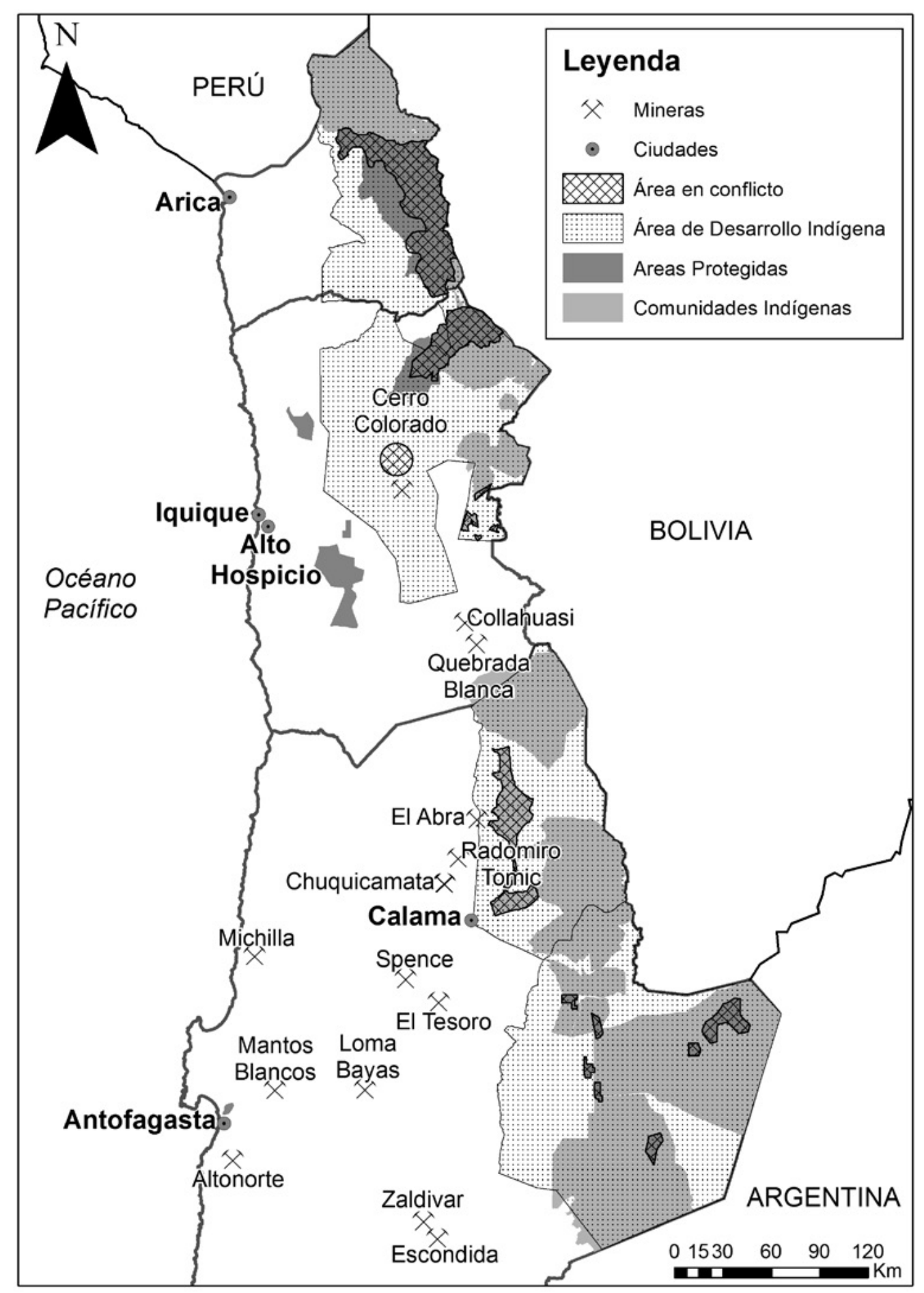

Figura 2. Emplazamiento de yacimientos mineros, áreas de conservación, comunidades y áreas de desarrollo indígena en el norte de Chile. Fuente: Elaboración propia. 
en el poblado de Cancosa (cercano a la frontera con Bolivia), con sus tierras comunales y prácticas de pastoreo circundante a un humedal, y la parte de la comunidad que emigró áreas urbanas como Pica y Alto Hospicio, y que corresponde a la nuevas generaciones. Si bien los hechos se iniciaron en la década de 1980 sus repercusiones continúan en la actualidad.

El humedal de Pampa Lagunillas se localiza a $120 \mathrm{~km}$ de la ciudad de Iquique y a $2.600 \mathrm{msnm}$, en la región de Tarapacá. El humedal está emplazado en el predio de nombre Huantija, que a su vez es parte de los territorios ancestrales reivindicados por dos comunidades indígenas aymaras: Cancosa y Lirima. En el área del humedal Lagunillas los aymaras habrían desarrollado ancestralmente actividades de ganadería a partir del sistema de acuíferos. La comunidad de Cancosa consiguió su personalidad jurídica como Comunidad Indígena reconocida por Conadi en 1995. Según diferentes fuentes y las entrevistas que hemos realizado en la zona, dicha comunidad se compone de más de 80 familias, lo que totaliza unas 350 personas asociadas a una aldea rural localizada en plena cordillera de los Andes, a $3.962 \mathrm{msnm}$. El Censo 2002 (el último válidamente realizado en Chile), indicó que en dicha localidad vivían solo 26 habitantes, y que 20 personas más, de origen aymara, componían la población flotante enfocada a cuidar el ganado y plantaciones agrícolas de subsistencia. El grueso de los miembros de la comunidad se encuentra disperso en zonas urbanas como Pica, Alto Hospicio e Iquique.

Desde antes de los años sesenta, se realizaron estudios en los afloramientos de óxidos en el sector de la Quebrada de Parca, los cuales revelaron la existencia de recursos cupríferos en el llamado Cerro Colorado. Los sondajes llevados a cabo por el grupo chileno-norteamericano Normina, confirmaron esta situación y la posibilidad de explotar un futuro yacimiento. En la década del setenta, Nipon Mining Company, compró el yacimiento y culminó las campañas de exploraciones, estimando una reserva de 79 millones de toneladas de cobre. Hacia el año 1982 la corporación canadiense Río Algom, a través de su subsidiaria Riochilex, compró la propiedad y creó la Compañía Minera Cerro Colorado, la cual se volvió realmente efectiva en el año 1992 cuando comenzó la construcción de su planta, considerando la explotación a tajo abierto, iniciando su fase operacional con la concreción del primer cátodo de cobre en 1994. Dicha corporación explotó el yacimiento cuprífero hasta el año 2000 cuando es comprada por BHP.

Este hecho, producirá un punto de inflexión para las comunidades indígenas relacionadas con CMCC, ya sea por su cercanía a la faena o por su relación con el proceso productivo. Hasta aquel momento, las relaciones entre ambos actores no se encontraban institucionalizadas, con excepción de la comunidad de Cancosa, a la cual se le arriendan sus derechos de aguas sobre el sistema lacustre Lagunillas. A pesar de que las comunidades de la precordillera son las más cercanas a la operación de CMCC, fueron las comunidades altiplánicas las primeras en reaccionar ante la compañía minera, en la defensa principalmente del recurso hídrico, articulándose bajo nuevos formatos organizativos, asumiendo en este proceso una transformación política de sus bases en defensa de sus recursos naturales y su patrimonio ancestral. De esta forma, el conflicto socioambiental será fundante en la organización actual de los aymaras de Tarapacá, y les permitirá abordar de mejor manera el proceso de reconocimiento que deriva de la Ley Indígena en 1993. Como destacan Gundermann (2000) y Van Kessel (2003, 1985), el caso de CMCC y sus exploraciones en la década de 1980, dio nacimiento a una de las primeras organizaciones de las propias comunidades de defensa de sus recursos naturales, la cual fue llamada Cotali. Este hecho se enmarca dentro de las acciones de exploración de aguas subterráneas que CMCC inició en 1981, sin la autorización de las comunidades aymaras de la zona (Salinas 2012). Posteriormente, en 1982 se estableció un contrato de arriendo entre la CMCC y la comunidad aymara de Cancosa sobre las aguas de Lagunillas.

Éste es uno de los primeros casos de inscripción de agua subterránea de una compañía minera, amparado en el nuevo Código de Aguas (1981), en el contexto del escaso conocimiento de la situación de los recursos hídricos a más de 100 metros de profundidad y de lo que significaba la producción intensiva de minerales (Mamani 2008). La Dirección General de Aguas (DGA) le otorgó a CMCC el derecho de aprovechamiento de $300 \mathrm{l} / \mathrm{seg}$ en 1982, de los cuales la empresa solo utilizó $901 / \mathrm{seg}$. La Compañía adquirió el derecho de servidumbre de paso, otorgada por el Estado de Chile, para un acueducto de $76 \mathrm{~km}$, el cual va desde Huantija hacia la faena minera, 
pasando directamente por la comunidad de Parca, lo que según los dirigentes ha significado una reducción de los acuíferos y la disminución de la agricultura. Sin embargo, ya desde 1985 habían existido tensiones entre la compañía minera y la comunidad indígena de Cancosa, principalmente centradas en las compensaciones, la compra de terrenos, y la cantidad de agua que se estaba extrayendo (Mamani 2008). Al mismo tiempo, la situación de arrendamiento de tierras y aguas para la CMCC ocasionó un conflicto entre las comunidades indígenas de Cancosa y Lirima que se solucionó con la compra del fundo Huantija por parte de la CMCC en 1993 (Salinas 2012) o 1996 (Avilés 2010). De esta forma, CMCC consiguió las aguas de pozos profundos ubicados en Lagunillas para tener una producción anual de 125 mil toneladas de cátodos de cobre de alta pureza, con una reserva estimada en 192 millones de toneladas de cobre, lo que ha generado impacto medioambiental sobre el sistema hídrico, afectando especialmente a la agricultura y la ganadería (Larraín y Poo 2010), pero también, sobre la forma en la cual se organizan las comunidades, su relación y repertorio de acción frente a la empresa minera y el Estado, e incluso las relaciones entre las comunidades aymaras y con los quechuas: "el principal cambio ha sido sobre la gente" (empresario local del pueblo de Mamiña, 2015).

Desde el año 2002 se viene registrando por parte de la comunidad de Cancosa el desecamiento de vertientes y la afectación al espejo del agua de Lagunillas (Figura 3). La DGA confirmó la reducción del acuífero durante el año 2005, y la Corporación Regional del Medio Ambiente (Corema) de Tarapacá sancionó a BHP Billiton por el daño ambiental en Lagunillas en 2006. Ese mismo año la comunidad aymara de Cancosa interpuso acciones legales contra Cerro Colorado por el daño psicosocial, patrimonial, daño moral colectivo y daño futuro a raíz del desecamiento del humedal. Dentro de las actividades de desarrollo local promovidas por los programas estatales para población indígena, la comunidad de Cancosa había comenzado un proyecto de turismo y plantación de quínoa, ambas iniciativas apoyadas por el Programa Orígenes, dentro de un plan mayor sobre repoblamiento del sector andino enmarcado en la declaración de la zona como ADI Jiwasa Oraje (2001). Al momento de escalar el conflicto, la gran mayoría de los que habían firmado el contrato de arriendo en nombre de la comunidad aymara de Cancosa ya habían fallecido, por lo que todas estas ac- ciones fueron emprendidas por miembros de la nueva generación, criados principalmente en zonas urbanas, con acceso a información y con un amplio dominio de lenguaje técnico y legal (por ejemplo se encargaron estudios hidrogeológicos propios), lo que permitió a la comunidad establecer una negociación con la CMCC sin precedentes.

Producto de las negociaciones, la CMCC emprendió un trabajo de recuperación del humedal de Lagunillas y se logró en el año 2008 un acuerdo extrajudicial con la comunidad, que en conjunto con la empresa estableció un plan de trabajo para continuar la recuperación del ecosistema y de apoyo al desarrollo de los miembros de ésta. Entre los puntos de negociación se incluyó un plan de seguimiento para la recuperación de Lagunillas al 2030, el financiamiento de un programa de fomento productivo al año 2027, y un plan de educación hasta el año 2030 (Salinas 2012). En síntesis, el conflicto se constituyó como un caso cuya causa está en que: "la comunidad es propietaria de estas aguas, no solo porque están localizadas en territorios ancestrales, sino también porque han hecho uso ancestral de ellas a través de su afloración en el acuífero de Lagunillas, que abarca una amplia extensión de tierras de propiedad y uso de la comunidad" (Yáñez y Molina 2014). Se reconoció el daño ambiental por parte de la DGA y se llegó a un plan de mitigación y compensaciones con la comunidad indígena de Cancosa.

Como lo ilustra la Figura 3 , es posible observar que existe un descenso paulatino del cuerpo de agua (representado por la línea continua) desde finales de la década del 1980 hasta inicios de los 2000, con su punto mínimo entre los años 2004 y 2006 , para luego presentar un leve aumento hacia el año 2009 y 2014 (no hemos tenido acceso a imágenes de la década del noventa). Este descenso coincide con el período en el cual se desarrolló el conflicto socioambiental. El aumento registrado el año 2009 puede coincidir con la implementación de las medidas compensatorias por parte de la compañía propietaria de los derechos de agua cercanos a Lagunillas con el objeto de disminuir el impacto, dado que, según los datos de la estación pluviométrica, dicha disminución y aumento no se condicen con los datos de precipitación (como lo muestra la Figura 4). De acuerdo a ellos, la precipitación para los años 2009 y 2014 es inferior a los años 2004 y 2006, que es cuando el cuerpo de agua se encontraba en su punto mínimo de superficie, lo que confirma que el 


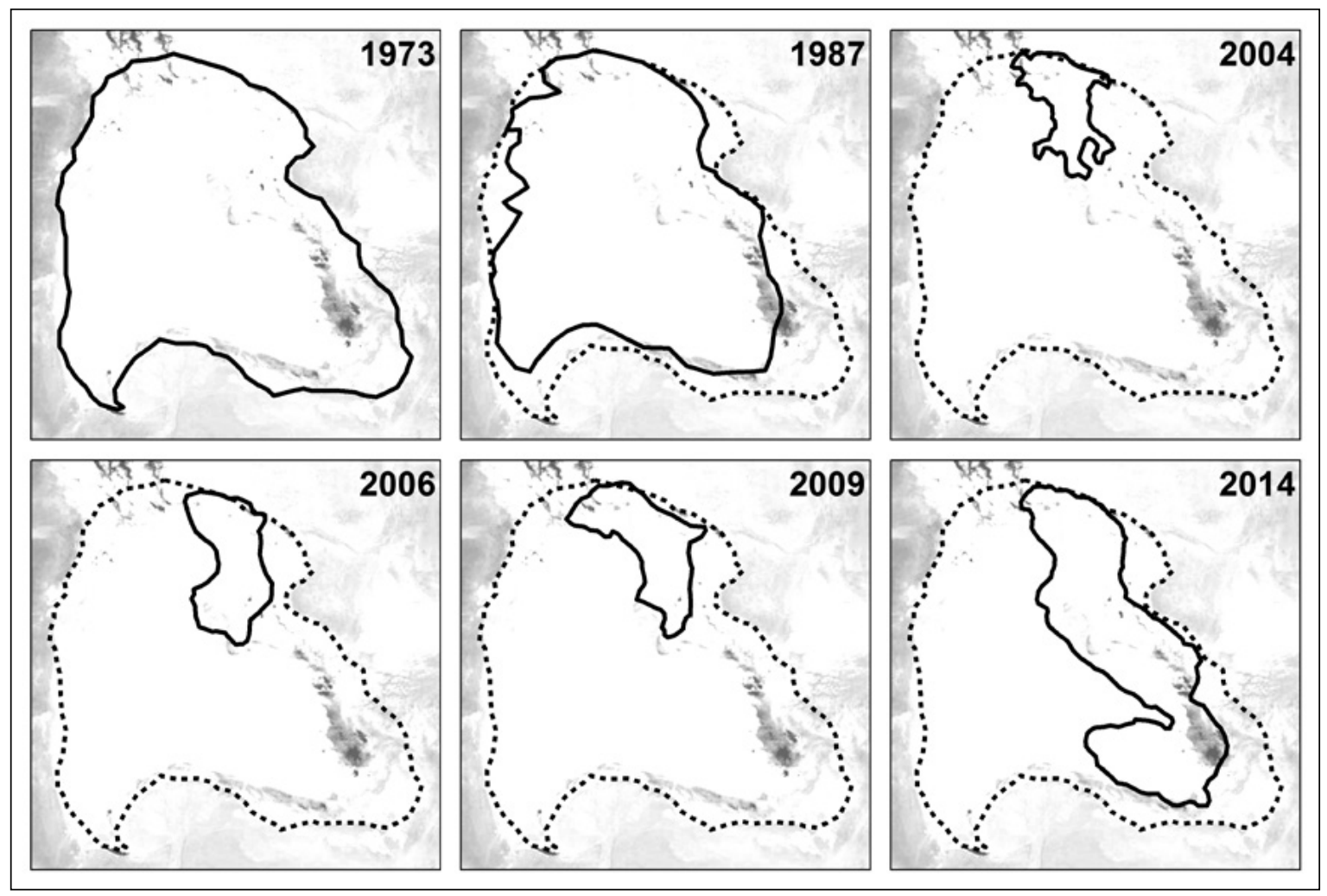

Figura 3. Variación del cuerpo de agua de Lagunillas Fuente: Elaboración propia.

aumento posterior al 2009 pueda deberse a medidas de mitigación más que a precipitación.

En una de las entrevistas realizadas a uno de los miembros de la comunidad de Cancosa, se nos señaló que existe preocupación debido a que la estrategia de un proyecto de desarrollo local orientado al turismo no había funcionado como ellos esperaban, y que se creía que la continuidad de este proyecto presentaba dificultades, especialmente porque las generaciones más jóvenes no tenían mucho interés en volver a Cancosa a vivir y trabajar. De la misma forma, en nuestra visita al humedal de Lagunillas pudimos observar que se han tomado medidas para mantener el espejo de agua, pero distaría mucho, de acuerdo a nuestros entrevistados, de cómo era el lugar antes de la intervención de la CMCC (ver Figura 3). En una entrevista con un informante clave se nos mencionó que la recuperación del humedal no estaba funcionando, y que existía la idea de que ésta tomaría mucho tiempo, si es que antes esta preocupación ambiental por este humedal no cayera eventualmente en el olvido.
Sin embargo, y como señala un encargado de relaciones comunitarias de una de las empresas mineras de Tarapacá, junto con el daño ambiental, uno de los principales impactos fue el haber establecido un sistema de negociación basado en la compensación económica y el que las empresas mineras hayan asumido una suerte de rol subsidiador con las comunidades indígenas (dotándolas de servicios básicos, incentivos y fondos concursables) que las hizo suplir en muchas localidades la inexistente acción estatal. Esto creó un nuevo escenario en la región de Tarapacá: gran inversión privada demandando tierras, agua y mano de obra en el marco de grandes reformas neoliberales, y comunidades indígenas que por primera vez fueron posibilitadas de ser reconocidas en cuanto a su existencia y ocupación territorial ancestral y actual por parte del Estado, y de ser compensadas por la extracción de recursos y el impacto de las faenas en sus territorios por medio de las mineras. El siguiente paso fue la ampliación de las disputas territoriales derivadas del extractivismo, el neoliberalismo multicultural y la articulación 


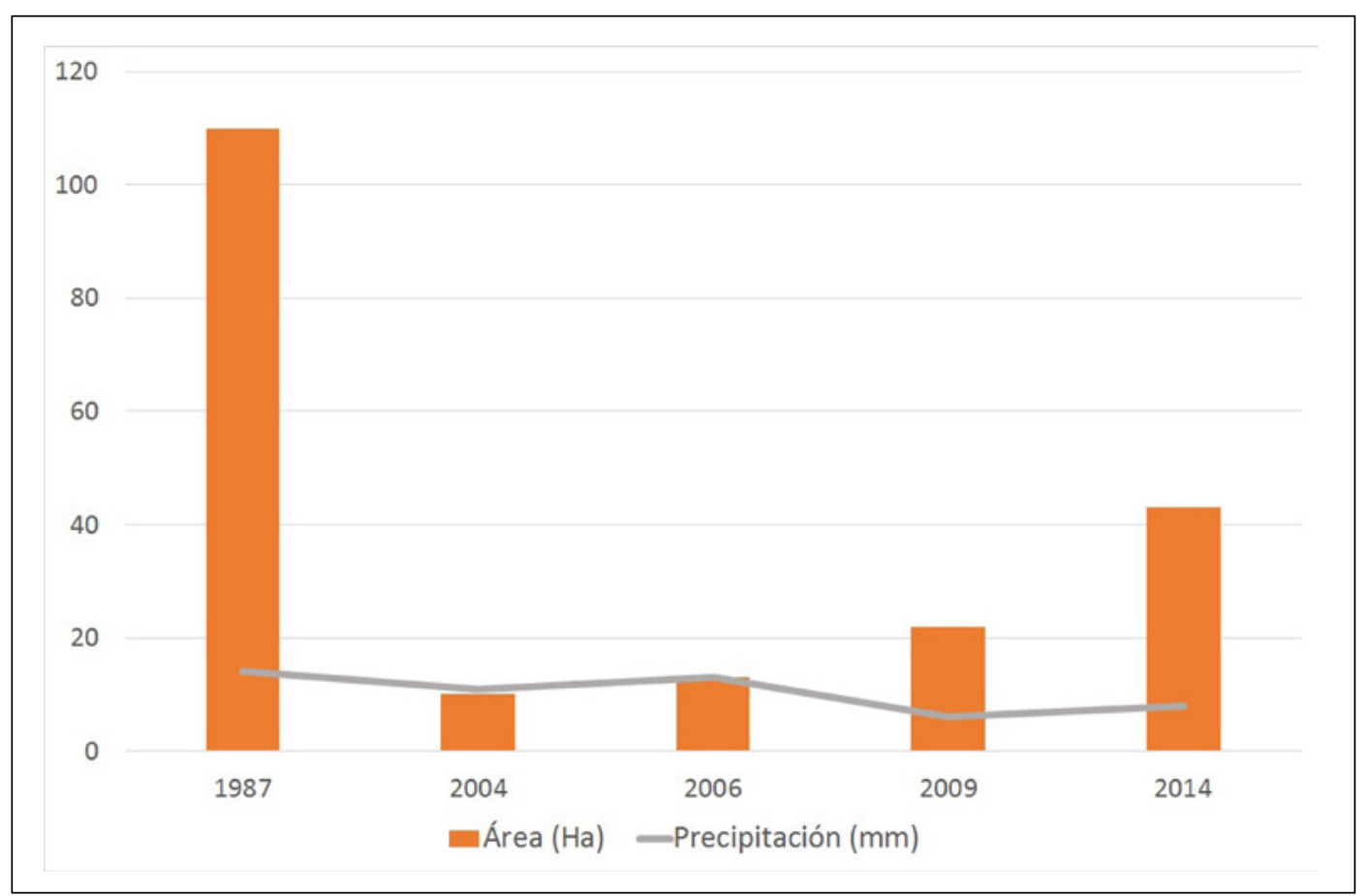

Figura 4. Comparación entre área del cuerpo de agua de Lagunillas y precipitación Fuente: Elaboración propia, en base a digitalización y datos de la DGA.

identitaria: nuevas comunidades comenzaron a organizarse, el daño ambiental sobre los recursos hídricos producido por las mineras se transformó en un potente discurso de las comunidades y de activistas medioambientales, las medidas de mitigación y compensación se transformaron en la forma de relación ente comunidades y empresas, y estas últimas no han sido lo suficientemente efectivas para incentivar procesos de desarrollo local en las comunidades andinas y precordilleranas.

\section{$*$ Conclusión}

El extractivismo minero en Chile es el resultado de una reestructuración mundial de la industria minera y de la existencia de un marco legal neoliberal implantado durante la dictadura, pero aplicado en términos materiales en democracia. El Estatuto de Inversiones Extranjeras, el Código de Aguas, la Ley Minera, e incluso la Declaración de parques nacionales ilustran que el neoliberalismo es un proyecto ecológico político estatal, que ha permitido el boom minero de Tarapacá, y de otras zonas de Chile, a partir de la concentración de derechos de agua y de concesiones de tierra, provocando transformaciones en la zona altiplánica y precordillerana y contradicciones socioterritoriales de importancia.

Desde estas contradicciones socioterritoriales es importante leer la articulación identitaria y la reorganización de las comunidades indígenas de Tarapacá. En este proceso, han confluido la persistencia de la comunidad, que se ha adaptado a la nueva vida urbana, a las políticas emanadas de los organismos del Estado para rescatar y fortalecer un determinado tipo de identidad indígena, y las políticas comunitarias desarrolladas por las empresas mineras, entre otros. Las comunidades hoy en día están organizadas, son visibles y mantienen relaciones complejas, donde confluyen elementos de resistencia y negociación. Incluso en la zona de impacto de la CMCC la emergencia de los quechuas en los poblados de Macaya, Mamiña y Quipisca es un hecho bastante importante, donde la conflictividad asociada a la presencia de la minera ha jugado un rol primordial.

También hemos sugerido que pensar en contradicciones socioterritoriales permite analizar el conflicto socioambiental más allá de territorios adyacentes al área de extracción de minerales. Es necesario ampliar el análisis, 
integrando los lugares desde donde se extrae el recurso hídrico para los procesos industriales y para el abastecimiento de los campamentos, además de aquellas zonas donde existe afectación por el polvo en suspensión, o aquellos lugares donde se encuentran los relaves, o que son impactados por el tránsito de los vehículos. Al mismo tiempo, creemos importante considerar los asentamientos urbanos, como en el caso de Iquique y Alto Hospicio, que es donde reside el grueso de la población aymara y quechua de Tarapacá, y que se encuentran lejanos al área de extracción. Es en estos espacios urbanos donde viven los aymaras y quechuas que han nacido en la ciudad- desde donde se lleva a cabo parte de la articulación identitaria que reivindica los territorios de origen de las familias, movilizando discursos que los conectan con la ocupación indígena ancestral del mundo andino. Este hecho, sumado a las políticas nacionales e internacionales sobre pueblos indígenas, está generando una nueva geografía indígena, que contesta la relación entre pueblos indígenas y territorio, presionando al Estado y a las empresas mineras por beneficios compensatorios derivados de los efectos del extractivismo.

También es importante señalar la existencia del ADI Jiwasa Oraje, el cual contempla una alta densidad de comunidades indígenas y poblados que son declarados como impactados por la actividad minera y donde se están enfocando recursos del Estado utilizando el discurso de la disminución de la pobreza y la sustentabilidad ambiental. El que una zona declarada como ADI tenga en el centro una faena de extracción minera es parte de la contradicción territorial que explica los conflictos socioambientales. Pero también es importante darle una segunda lectura al hecho de que precisamente la presen- cia de Cerro Colorado ha fortalecido, mediante políticas de mitigación y compensación, el proceso de articulación identitaria y la reorganización de las comunidades.

De esta forma Lagunillas, con su degradación ambiental producto de la extracción de agua, con su comunidad traslocada y fuertemente concentrada en espacios urbanos, con negociación, medidas de compensación y plan de recuperación, ha sido producido como un paisaje minero, en el sentido en que Lefebvre, Harvey, Smith y Swyngedouw, entre otros, han comprendido la dialéctica de producción del espacio en el capitalismo. Esta producción está fuertemente conectada al proceso de articulación identitaria indígena mundial y a una red cuprífera global. De esta forma, un conflicto socioambiental no es solo un hecho puntual en un lugar aislado, donde se enfrentan un par de actores con intereses contrapuestos. Por el contrario, un conflicto socioambiental es un fenómeno multiescalar, histórico y coproducido tanto por el capitalismo global, como por instituciones multilaterales, ONG, intelectuales, y actores locales indígenas y no indígenas. Sin embargo, el daño ambiental y la transformación sociocultural ocurren de manera irreversible en los espacios locales. El tiempo dirá si las medidas de compensación negociadas entre empresas y comunidades han sido las adecuadas.

Agradecimientos Esta investigación ha sido financiada por el Proyecto FONDECYT de Iniciación $\mathrm{N}^{\circ}$ 11140265 y por el Centro de Estudios de Conflicto y Cohesión Social (COES), CONICYT/FONDAP N ${ }^{\circ}$ 15130009. Ha recibido también el aporte del Núcleo Acciones Colectivas en Chile (1990-2015) de la Universidad Andrés Bello. Asimismo queremos agradecer a Ximena Toledo por sus valiosos comentarios.

\section{$*$ Referencias citadas}

ALIMONDA, H. (Coord.). 2011. La Naturaleza Colonizada: Ecología Política y Minería en América Latina. Ediciones CICCUS, Buenos Aires.

ALIMONDA, H. 2015. Mining in Latin America: coloniality and degradation. En The International Handbook of Political Ecology, R. Bryant (Ed.), pp. 149-161. Edward Elgar Publishing, Cheltenham.

AVILÉS SUÁREZ, M. E. 2010. Percepción de la sustentabilidad socio ambiental por parte de comunidades indígenas aymaras de humedales altoandinos (Tesis para optar al grado de Magíster en Gestión y Planificación Ambiental). Universidad de Chile, Santiago.

AYLWIN, J., M. MEZA-LOPEHANDÍA y N. YÁÑEZ. 2013. Los Pueblos Indígenas y el Derecho. LOM Ediciones, Santiago.

BEBBINGTON, A., J. BURY, D. HUMPHREYS BEBBINGTON, J. LINGAN, J. MUÑOZ y M. SCURRAH. 2008. Mining and social movements: Struggles over livelihood and rural territorial development in the Andes. Working Paper 33, Brooks World Poverty Institute. University of Manchester, Manchester. 
BEBBINGTON, A. y M. WILLIAMS. 2009. Agua y Minería: Conflictos en el Perú. Mountain Research and Development 28: 190-195.

BEBBINGTON, A. (Ed.). 2013. Industrias extractivas, conflicto social y dinámicas institucionales en la región andina. Instituto de Estudios Peruanos, Lima.

BENGOA, J., N. CANIGUAN, D. DURÁN, M. ALLENDE, M. GERVAIN, F. VILLARROEL y P. GAJARDO. 2012. Mapuche. Procesos, políticas y culturas en el Chile del Bicentenario. Editorial Catalonia, Santiago.

BLÁZQUEZ, P. 1999. El Agua del Loa Superior; 1888-1920. Administración Estatal de un recurso escaso (Tesis para optar al grado de Licenciado en Historia). Instituto de Historia, Pontificia Universidad Católica de Chile, Santiago.

BOCCARA, G. y P. BOLADOS. 2008. ¿Dominar a través de la participación? El neoindigenismo en el Chile de la postdictadura. Revista Memoria Americana 16(2): 167-196.

BRIDGE, G. 1999. Harnessing the bonanza: economic liberalization and capacity building in the mineral sector. Natural resources 23(1): 43-55.

BRIDGE, G. 2000. The social regulation of resource access and environmental impact: production, nature and contradiction in the US copper industry. Geoforum 31(2): 237-256.

BRIDGE, G. 2004. Mapping the bonanza: geographies of mining investment in an era of neoliberal reform. The Professional Geographer 56(3): 406-421.

BUNKER, S. 2011. Matéria, Espaço, Tempo e Globalização: o Caso de Carajás na Amazônia Brasileira. En La Naturaleza Colonizada: Ecología Politica y Minería América Latina, H. Alimonda (Coord.), pp. 127-133. Ediciones CICCUS, Buenos Aires.

CARIOLA, C. y O. SUNKEL. 1982. Un Siglo de Historia Económica de Chile, 1830-1930. Ediciones Cultura Hispánica, Madrid.

CARRASCO, A. y E. FERNÁNDEZ. 2009. Estrategias de Resistencia Indígena frente al Desarrollo Minero. La Comunidad de Likantatay ante un posible traslado forzoso. Estudios Atacameños. Arqueología y Antropología Surandinas 38: 75-92.

CASTRO, M. 1997. Agua, Derechos y Cultura en los Andes del Norte de Chile: Un Enfoque desde la Antropología Jurídica. Chungara 29(1): 63-80

CASTRO, M. y M. BAHAMONDES. 1987. Cambios en la Tenencia de la Tierra en un Pueblo de la Precordillera del Norte de Chile: Socoroma. Revista Chilena de Antropología 6:35-57.
CLIFFOR, J. 2013. Returns: becoming indigenous in the twenty-first century. Harvard University Press, London.

DELGADO, G. 2010. Ecología Política de la Minería en América Latina: Aspectos socioeconómicos, legales y ambientales de la mega minería. Centro de Investigaciones Interdisciplinarias en Ciencias y Humanidades, Ciudad de México.

ESCOBAR, A. 1999. After Nature: Steps to an Antiessentialist Political Ecology. Current Anthropology 40(1): 1-30.

ESCOBAR, A. 2011. Ecología Política de la Globalidad y la Diferencia. En La Naturaleza Colonizada: Ecología politica y minería en América Latina, H. Alimonda (Coord.), pp. 61-92. Ediciones Ciccus, Buenos Aires.

GONZÁLES, S. 2011. Las históricas relaciones entre Tarapacá y Oruro: la frustrada tentativa de integración transfronteriza durante el ciclo de expansión del salitre (1864-1928). Revista de Geografía Norte Grande 50: 63-85.

GAVILÁN, V. y F. LAGOS. 2014. ¿Integración social y subordinación política de los aymara? Un estudio de la certificación estatal indígena en el norte chileno. Estudios Atacameños. Arqueología y Antropología Surandinas 49: 95-110.

GÖBEL, B. y A. ULLOA (Eds.). 2014. Extractivismo minero en Colombia y América Latina. Colección General Biblioteca Abierta, Bogotá.

GONZÁLES, S. 2002. Chilenizando a Tunupa: La escuela pública en el Tarapacá andino 1880-1990. Ediciones de la Dirección de Bibliotecas, Archivos y Museos, Santiago.

GREBE, M. E. 1998. Procesos migratorios, identidad étnica y estrategias adaptativas en las culturas indígenas de Chile: Una perspectiva preliminar. Revista Chilena de Antropología 14: 55-68.

GUDYNAS, E. 2009. Diez tesis urgentes sobre el nuevo extractivismo. Contextos y demandas bajo el progresismo sudamericano actual. En Extractivismo, Política y Sociedad. CAAP y CLAES, Quito.

GUDYNAS, E. 2015. Extractivismos: Ecología, economía y política de un modo de entender el desarrollo y la Naturaleza. Centro de Documentación e Información Bolivia (CEDIB), Cochabamba.

GUERRERO, V. 1995. De parcela a comuna: la producción de espacio social en Alto Hospicio. Revista Ciencias Sociales 5: 18-41.

GUNDERMANN, H. 2000. Las organizaciones étnicas y el discurso de la identidad en el norte de Chile, 1980-200o. Estudios Atacameños. 19: 75-92. 
GUNDERMANN, H. 2004. Inicios de Siglo en San Pedro de Atacama: Procesos, Actores e Imaginarios en una Localidad Andina. Chungara. Revista de Antropología Chilena 36: 221-239.

GUNDERMANN, H. y H. GONZÁLEZ. 20o8. Pautas de Integración Regional. Migración, Movilidad y Redes Sociales en los Pueblos Indígenas de Chile. Universum 23(1): 82-115.

GUNDERMANN, H. y J. VERGARA. 2009. Comunidad, Organización y Complejidad Social Andinas en el Norte de Chile. Estudios Atacameños. Arqueología y Antropología Surandinas 38: 107-126.

HALL, S. 1990. Cultural Identity and Diaspora. En Identity: Community, Culture, Difference. J. Rutherford (Ed.), pp. 222-237. Lawrence \& Wishart, U.K.

HALL, S. y P. DU GAY (Eds.). 1996. Questions of cultural identity. Sage, London.

HIDALGO, J. 2004. Historia Andina de Chile. Editorial Universitaria, Santiago.

INSTITUTO NACIONAL DE ESTADÍSTICAS. 1992. Censo de Población y Vivienda Chile 1992, Resultados Generales. Recuperado el 20.10.2015 del sitio web http://www.ine.cl/canales/ usuarios/cedoc_online/censos/pdf/censo__1992.pdf

\section{INSTITUTO NACIONAL DE ESTADÍSTICAS Y PROGRA-} MA ORÍGENES. 2005. Estadísticas Sociales de los Pueblos Indígenas en Chile, Censo 2002. Recuperado el 22.10.2015 de http://www.ine.cl/canales/chile_estadistico/estadisticas_sociales_culturales/etnias/pdf/estadisticas_indigenas_2002_11_09_09.pdf

ISAGER, L. and S. IVARSSON. 2010. Contesting Landscapes in Thailand: Tree Ordination as Counter-territorialization. Critical Asian Studies 34(3): 395-417.

LARRAÍN, S. y P. POO (Eds.). 2010. Conflictos por el Agua en Chile: Entre los Derechos Humanos y las Reglas del Mercado. Programa Chile Sustentable, Santiago.

LEFF, E. 2006. Aventuras de la Epistemología Ambiental: de la articulación de ciencias al diálogo de saberes. Siglo XXI Editores, México.

LESTRELIN, G. 2011. Rethinking State Ethnic Minority Relations in Laos: Internal Resettlement, Land Reform and Counter-Territorialization. Political Geography 30: 311-319.

LI, T. 2000. Articulating indigenous identity in Indonesia: Resource politics and the tribal slot. Comparative studies in society and history $42(01): 149-179$.
MADALENO, I. 2004. Aymara Indians in Chile: Water Use in Ancestral Cultures at Odds with Water Rights in Modern Times. Conference on International Agricultural Research for Development, Berlín.

MAMANI, A. 2008. Desecamiento Laguna sector Lagunilla en el territorio ancestral de la comunidad de Cancosa. En Globalización, Derechos Humanos y Pueblos Indígenas, A. Bello y J. Aylwin (Comps.), pp. 392-397. Observatorio de Derechos de los Pueblos Indígenas y Alfabeta Impresiones, Temuco.

MARTINEZ-ALIER, J. 2004. Distribution Conflicts Ecological of Sustainability Indicators. International Journal of Political Economy 34(1): 13-30.

MEZA, R. 1983.100 años de minera en Chile. Sociedad Editora Lead, Santiago.

MILLÁN, A. 2006. La minería metálica en Chile en el Siglo XX. Editorial Universitaria, Santiago.

MOLINA, F. 2012. Competing rationalities in water conflict: Mining and the indigenous community in Chiu Chiu, El Loa Province, Northern Chile. Singapore Journal of Tropical Geography 33: 93-107.

MOLINA, F. 2014. Negotiated Rationalities, Politicised Identities: Intergenerational Relations, water conflicts and mining in Chiu-Chiu, Chile. (Thesis to obtain the degree of Doctor of Philosophy in Geography) Department of Geography, King's College, London.

MURRA, J. 1975. Formaciones Económicas y Políticas del Mundo Andino. IEP Ediciones, Lima.

NIEZEN, R. 2003. The Origins Indigenism: human rights and the politics of identity. University of California Press, London.

PELUSO, N. L. 1995. Whose Woods are These? Counter-Mapping Forest Territories in Kalimantan, Indones. Antipode 27(4):383-406.

PELUSO, N. L. 2005. Seeing Property in Land Use: Local Territorializations in West Kalimantan, Indonesia. Geografisk Tidsskrift, Danish Journal of Geography 105(1): 1-15.

PELUSO, N. y P. VANDERGEEST. 2015. Political Forest. En The International Handbook of Political Ecology, R. Bryant (Ed.), pp. 162175. Edward Elgar Publishung, U.K.

PERRAULT, T. Extracting Justice: Natural Gas, Indigenous Mobilization, and the Bolivian State. En The Politics of Resource Extraction: Indigenous Peoples, Multinational Corporations, and the State, S. Sawyer y Terence Gomez (Eds.), pp. 75-102. Palgrave Macmillan, London.

PERRAULT, T. y B. GREEN. 2013. Reworking the spaces of indigeneity: the Bolivian ayllu and lowland autonomy movements compared. Environment and Planning D: Society and Space 31: 43-60 
PRIETO, M. 2014. Privatizing Water and Articulating Indigeneity: The Chilean Water Reforms and the Atacameño People (Likan Antai). (Doctor of Philosophy in Geography) School and Geography Development, The University of Arizona, Tucson Arizona.

PRIETO, M. 2016. Transando el agua, produciendo territorios e identidades indígenas: el modelo de aguas chileno y los atacameños de Calama. Revista de Estudios Sociales 55: 88-103.

PRIETO, M. y C. BAUER. 2012. Hydroelectric Power Generation in Chile: An Institutional Critique of the Neutrality of Market Mechanisms. Water International 37(2): 131-146.

RIVERA, F. 1997. Procesos de articulaciones socioidentitarias y reformulaciones étnicas en Atacama. Estudios Atacameños 13: 61-73.

SALINAS, J. 2012. La Comunidad Aymara de Cancosa y los Acuerdos con la Compañía Minera Cerro Colorado. En Defensa de los Derechos Territoriales en Latinoamérica, M. Fernández y J. Salinas, pp. 211-248. RIL, Santiago.

SAWYER, S. y E. TERENCE GOMEZ. 2012. The Politics of Resource Extraction: Indigenous Peoples, Multinational Corporations, and the State. Palgrave Macmillan, London.

SVAMPA, M. 2011. Modelos de desarrollo, cuestión ambiental y giro eco-territorial. En La Naturaleza Colonizada: Ecología Política y Minería América Latina, H. Alimonda (Coord.), pp. 181-215. Ediciones CICCUS, Buenos Aires.

SVAMPA, M. y M. ANTONELLI (Eds.). 2009. Minería Transnacional, Narrativas del Desarrollo y Resistencias Sociales. Biblos, Buenos Aires.
ULLOA, A. 2005. The Ecological Native. Indigenous People's Movements and Eco-Governmentality in Colombia. Routledge, U.K.

VANDERGEEST, P. 1996. Mapping Nature: Territorialization of Forest Rights in Thailand. Society \& Natural Resources: An International Journal 9(2): 159-175.

VANDERGEEST, P. y N. PELUSO. 1995. Territorialization and State Power in Thailand. Theory and Society 24(3):385-426.

VAN KESSEL, J. 1980. Holocausto al progreso: Los aymaras de Tarapacá. Centro de Estudios y Documentación Latinoamericana, Amsterdam.

VAN KESSEL, J. 1985. La Lucha por el Agua de Tarapacá: la visión andina. Chungara 14: 141-155.

VAN KESSEL, J. 2003. Holocausto al Progreso: Los aymaras de Tarapacá. IECTA, Iquique.

YÁÑEZ, N. y R. MOLINA. 2008. La gran minería y los derechos indígenas en el norte de Chile. LOM Ediciones, Santiago.

YÁÑEZ, N. y R. MOLINA. 2011. Las aguas indigenas en Chile. LOM Ediciones, Santiago.

ZAPATA, C. 2007. Memoria e historia: El proyecto de una identidad colectiva entre los aymara de Chile. Chungara, Revista de Antropología Chilena 39: 171-183. 